\title{
First Degree Biological Relative
}

National Cancer Institute

\section{Source}

National Cancer Institute. First Degree Biological Relative. NCI Thesaurus. Code C161420.

Any individual related biologically to another individual and considered immediate family as in the case of a parent, sibling or child. 